\title{
Measles Virus Infection in the Placenta of Monozygotic Twins
}

Makiko Ohyama, M.D., Tomoko Fukui, M.D., Yukichi Tanaka, M.D., Keisuke Kato, M.D., Rikuo Hoshino, M.D., Tomoka Sugawara, M.D., Michiko Yamanaka, M.D., Rieko Ijiri, M.D., Tetsutaro Sata, M.D., Yasufumi Itani, M.D.

Divisions of Neonatology (MO, TF, RH, YI), Pathology (YT, KK, RI), and Obstetrics (TS, MY), Kanagawa Children's Medical Center, Yokahama, Japan; and Department of Pathology (TS), National Institute of Infectious Diseases, Tokyo, Japan

We report a case of monozygotic twins whose mother was infected with measles at 19 weeks' gestation. One of the twins died in utero at 32 weeks' gestation. The placenta of the stillbirth showed massive fibrin deposition, and some residual trophoblasts contained many inclusion bodies positive for measles virus antigen. Fetal organs and cells other than a few splenic lymphocytes showed no evidence of measles virus infection. The placenta of the surviving infant showed focal intervillous fibrin deposits, and only a few syncytiotrophoblasts were positive for measles virus antigen. At present, 7 months after the delivery, the surviving infant has not developed any sign of measles virus infection. Postpartum course of the mother has been uneventful, although high titers of serum anti-measles virus IgM persisted for 6 months after delivery. This case is informative in the following respects: the villous trophoblasts had diagnostic inclusion bodies and ultrastructural evidence of measles virus infection, the degree of viral involvement within the monochorionic placenta was uneven, both of the twins were virtually free from measles virus infection despite the marked involvement of the placenta, and measles virus infection had persisted in the monochorionic placenta for approximately 13 weeks.

KEY WORDS: Immunohistochemistry, Intrauterine fetal death, Measles virus, Placenta, Twins, Ultrastructure.

Mod Pathol 2001;14(12):1300-1303

Copyright $\odot 2001$ by The United States and Canadian Academy of Pathology, Inc.

VOL. 14, NO. 12, P. 1300, 2001 Printed in the U.S.A.

Date of acceptance: June 21, 2001

Address reprint requests to: Yukichi Tanaka, M.D., Division of Pathology, Kanagawa Children's Medical Center, 2-138-4 Mutsukawa, Minami-ku,

Yokohama City 232-8555, Japan; e-mail: p-cmck@gd5.so-net.ne.jp; fax: 81-45-742-7821.
It is well known that measles virus (MV) infection of the mother often causes fetal demise as well as maternal morbidity and mortality (1-4). The placental and fetal pathology of MV infection, however, have received little attention. To our knowledge, there has been only one report of placental features associated with MV (5). We encountered a case of monozygotic twins whose mother was infected with MV at 19 weeks of gestation. One of the twins died in utero at 32 weeks' gestation, and the mother showed serological findings of persistent MV infection for 4 months after delivery. We present the clinicopathological findings of the monozygotic twins and the mother and describe the significance of histopathologic examination of the placenta.

\section{CLINICAL SUMMARY}

The gravida-1, para-1 mother was a 30 -year-old Japanese woman. She had not received MV vaccination nor been infected with MV. The present pregnancy was complicated with twinning, and cervical cerclage was performed to prevent premature delivery at 14 weeks of gestation. At 19 weeks of gestation, the mother developed fever and rash. Koplik's spots were noted on physical examination. She was diagnosed with primary MV infection and was temporarily hospitalized without notable complication. At 32 weeks of gestation, fetal heartbeat of one of the twins was not detected, and the death was confirmed by ultrasonography. The cardiotocograms of both twins had shown reactive patterns until the previous day. The mother was transferred to our center because of suspected fetal distress of the surviving co-twin. Emergency caesarean section was performed. A 1534-g stillborn male infant was delivered, and the autopsy was performed after 2 hours. The co-twin was an asphyxiated 1594-g male infant whose Apgar score was 2 and 5 at 1 and 5 minutes, respectively. The infant developed respi- 
ratory distress and required mechanical ventilation and intratracheal semisynthesized surfactant lavage. He was moderately anemic at birth, with 11.0 g/dL of hemoglobin, but did not show any signs of MV infection, including exanthema or enanthema. His serum anti-MV antibody was detected $(256 \times$ on complement fixation assay), but MV-specific immunoglobulin $\mathrm{M}$ (IgM) was negative. Postpartum course of the mother was not complicated, although high titer of MV-specific $\operatorname{IgM}(6.9,4.6,2.8$ cutoff index, negative less than 0.8 ) was noted right after and at 1 month and 4 months after the delivery, respectively. MV-specific IgM has become negative at the checkup 6 months after the delivery.

\section{MATERIALS AND METHODS}

The placenta was examined before fixation according to the modified method of Benirschke (6). Air injection was performed to confirm vascular anastomosis. The placenta and the visceral organs of the stillbirth were fixed in $10 \%$ buffered formalin, embedded in paraffin, cut into $3-4-\mu \mathrm{m}$ sections, and stained with hematoxylin and eosin (H\&E). Selected sections were immunostained by indirect immunoperoxidase method with antibody against human chorionic gonadotropin (hCG; DAKO, Kyoto, Japan) and cytokeratin (clone CAM 5.2; Becton-Dickinson, Mountain View, CA). Immunohistochemical examination for measles virus infection using rabbit anti-measles nucleocapsid protein antibody was performed on the fetal spleen, lung, liver, kidney, lymph nodes, trachea and the placenta as described elsewhere (7). Several $1-\mathrm{mm}^{3}$ fragments of the placental tissue were retrieved from the formalin-fixed material and were processed for electron microscopy. In brief, trimmed blocks were rinsed in sucrose-containing phosphate buffered saline, fixed in glutaraldehyde and osmium tetrachloride, and embedded in Epon. Ultrastructural observation was performed after uranyl acetate and lead citrate double stain by JEM 1010 (JEOL, Akishima, Japan).

\section{RESULTS}

\section{Pathologic Findings of the Placenta}

The placenta was diamniotic and monochorionic, confirming monozygotic origin of the twins. It weighed $840 \mathrm{~g}$ (including free membranes and the cords) and measured $23 \times 22 \times 2.5 \mathrm{~cm}$ before fixation. The septum divided the fetal surface in a $4: 6$ ratio (the smaller area belonged to the stillbirth). The umbilical cord of the stillborn showed marginal insertion. There were two large surface (arterio-arterial, and veno-venous) and one deep arterio-venous vascular anastomosis on the fetal surface. The fetal surface was greenish tan in color, and the maternal sur- face revealed marked fibrin deposition in the stillborn's area. On cut sections, perivillous, intervillous, and decidual fibrin deposition were prominent in the stillbirth's placenta (Fig. 1). Histologic examination of the stillbirth's placenta revealed extensive fibrin deposition from the subchorionic space to the decidual area, occupying approximately $70 \%$ of the volume. X-cell proliferation was prominent. Some areas were completely infarcted with ghost-like villi. Scattered neutrophils and collections of karyorrhectic cells were observed in the intervillous space (Fig. 2A). Some syncytiotrophoblastic cells had intranuclear and intracytoplasmic inclusion bodies (Fig. 2B). On immunocytochemistry, such trophoblastic cells were positive for MV antigen (Fig. 2C). These trophoblastic cells were also positive for hCG and cytokeratin. The decidual cells were negative for hCG, cytokeratin, and MV antigen. Ultrastructural study showed intranuclear (smooth form) and intracytoplasmic (fuzzy form) tubular viral structures consistent with MV (Fig. $3)$. No active villitis was observed in the nonnecrotic areas.

The chorion, amnion, and umbilical cord showed no inflammatory changes. Meconium-laden macrophages were occasionally seen in the chorionic plate. The livebirth's placenta showed no overt inflammatory reaction or viral inclusion in the villous tissue but showed intervillous fibrin deposits with moderate degree. Few villi entrapped in fibrin deposits were positive for MV antigen.

\section{Autopsy of the Stillbirth}

External appearance of the stillbirth was unremarkable, and no congenital malformation was observed. Microscopically, the liver and the lung showed marked congestion and hemorrhage. No

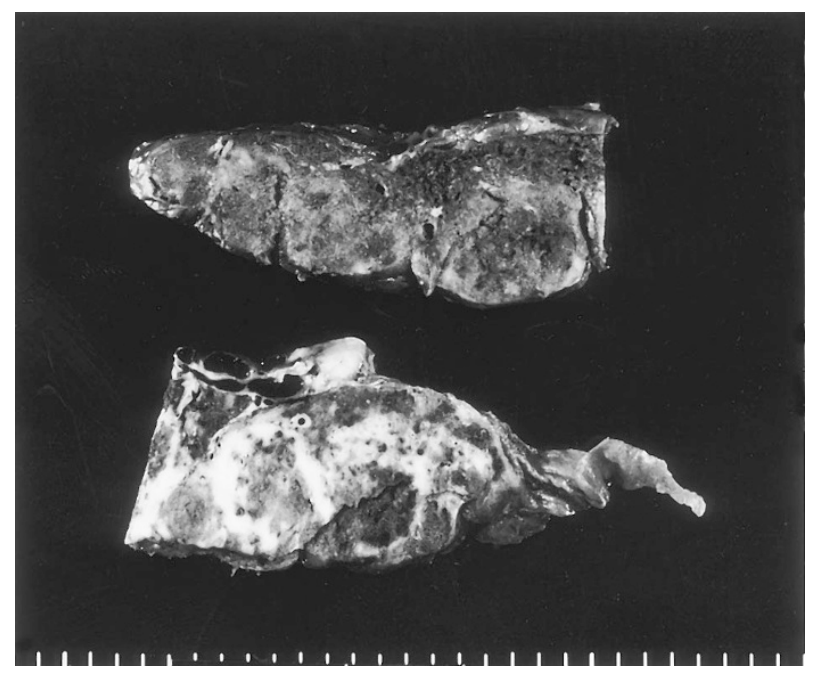

FIGURE 1. Gross feature of the placenta. On cut section, the stillbirth's area (lower) showed marked subchorionic, intervillous, and decidual fibrin deposition. The live birth's area (upper) was less affected. 

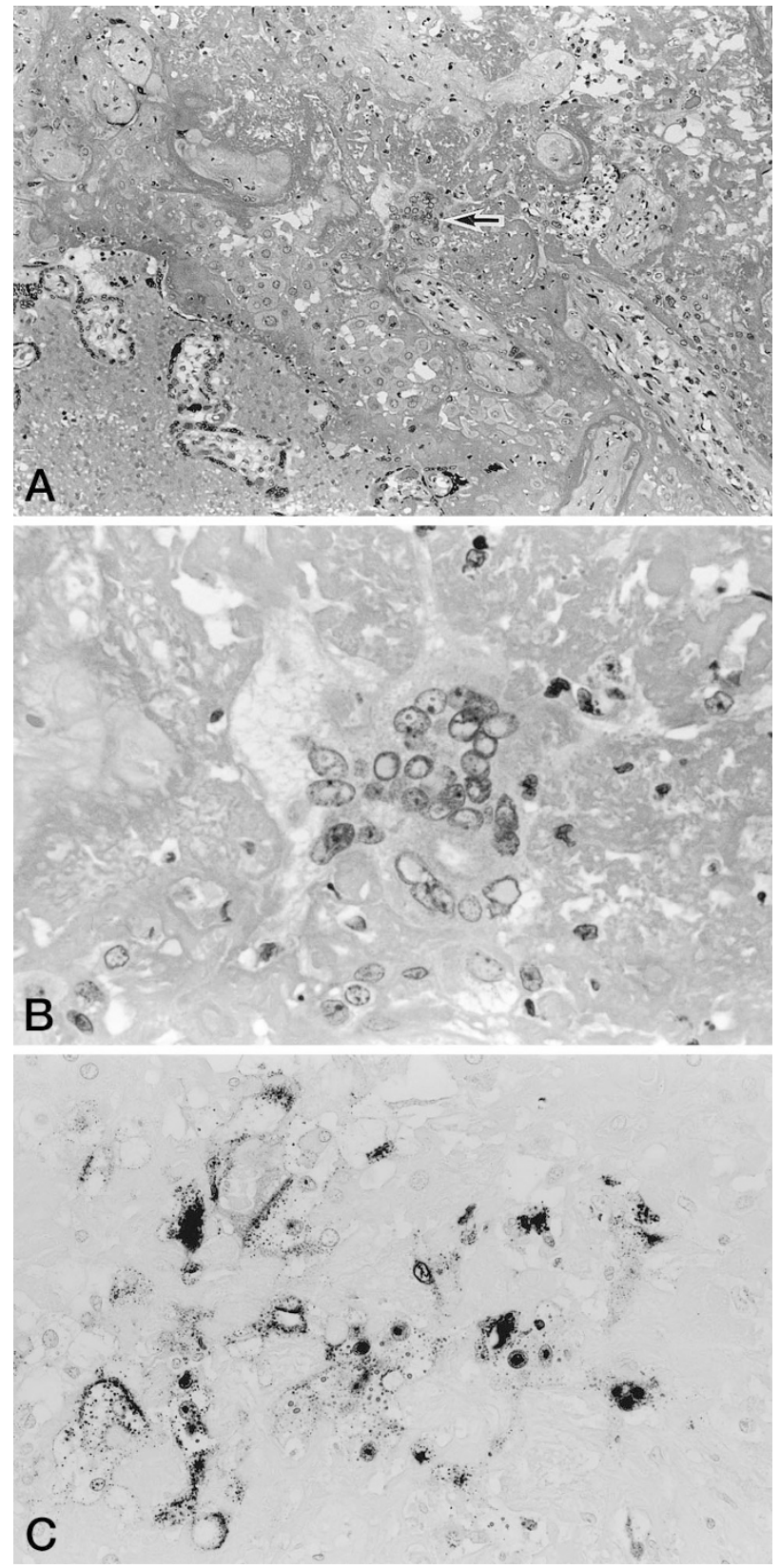

FIGURE 2. Histology of the placenta of the stillbirth. A, more than half the placenta was occupied with fibrin with X-cell proliferation $(\mathrm{H} \& \mathrm{E}, 40 \times)$. Arrow, the trophoblastic cells with intranuclear inclusions. B, scattered trophoblastic cells in the necrotic area, showing intranuclear inclusions $(\mathrm{H} \& \mathrm{E}, 200 \times)$. C, immunostain for measles virus antigen, showing positive reactions in both nuclei and cytoplasms (hematoxylin counterstain, $200 \times$ ).

multinucleated giant cell-bearing inclusion body was found in any organ of the fetus. No MV antigen was demonstrated in any organ other than the spleen, in which there were a few scattered lymphoid cells positive for this antigen.

\section{DISCUSSION}

In the postvaccine era, a much larger proportion of MV infection has occurred in the reproductive

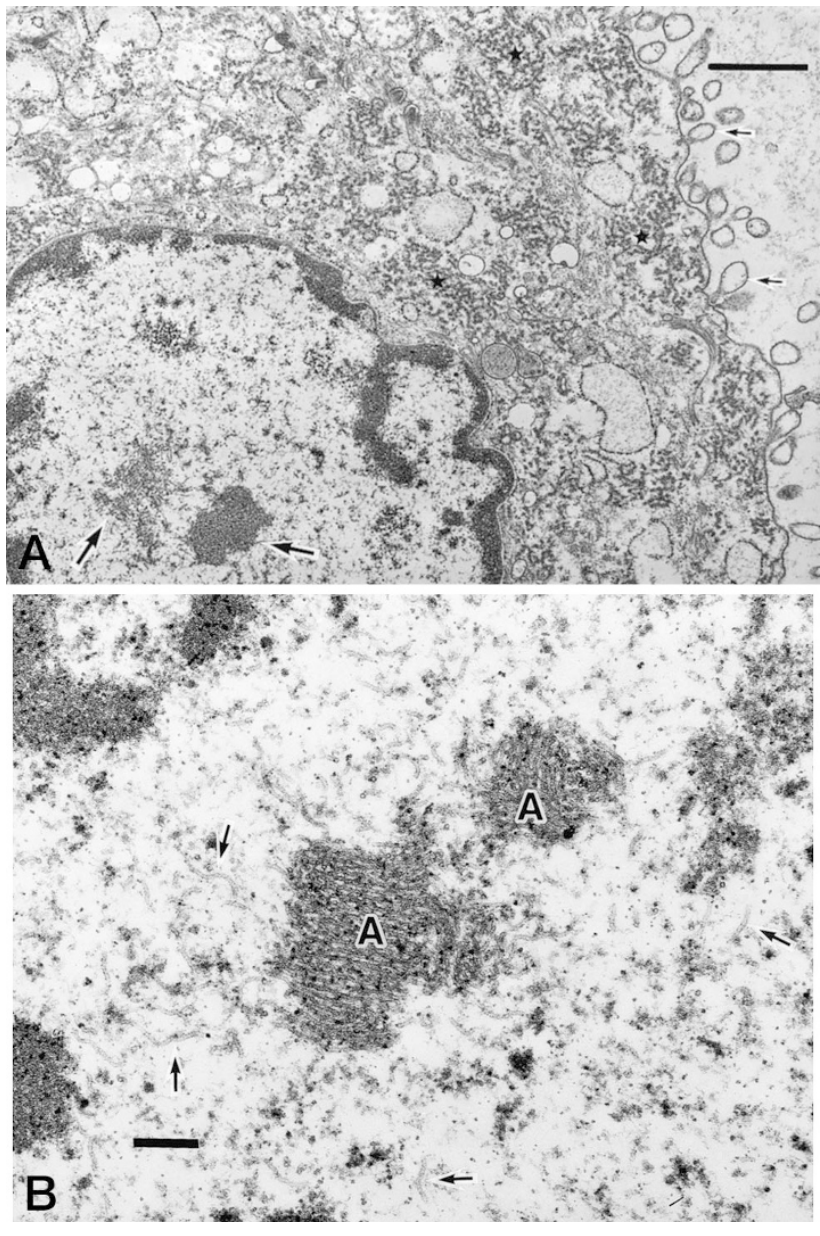

FIGURE 3. Ultrastructural findings. A, trophoblast with cytoplasmic processes (small arrows), containing intranuclear (smooth form, large arrows) and intracytoplasmic (fuzzy form, asterisks) inclusions produced by measles virus $(12,000 \times$; bar $=1 \mu \mathrm{m})$. B, intranuclear viral microtubules approximately $15 \mathrm{~nm}$ in diameter $(30,000 \times)$. A: aggregated viral microtubules; arrows: solitary viral microtubules. Bar $=200 \mathrm{~nm}$.

age group (8). It has been well known that MV infection of pregnant women often causes fetal distress and stillbirth as well as maternal morbidity and mortality (1-4). However, little attention has been paid to placental pathology of MV infection and transplacental infection of MV into the fetal organs. To our knowledge, only one report referred to MV infection of the placenta (5). In the article, the mother was infected with MV at 28 weeks of gestation, and the fetus succumbed to intrauterine death 13 days after that. Those investigators detected MV antigen by immunohistochemistry in the syncytial trophoblasts and decidua, but they provided neither diagnostic viral inclusion in these cells nor ultrastructural observation. In the present case, the trophoblasts often contained diagnostic viral inclusions that proved to be characteristic tubular structures ultrastructurally. Because villous trophoblasts usually express CD46 (9), one of the primate-specific receptors for MV (10), susceptibility of trophoblasts to MV is understandable. Fetal 
death or termination of pregnancy mostly occurs within 2 weeks after the maternal MV infection (1-4). In the present cases, both fetuses had grown appropriately for gestational age for more than 3 months after the maternal MV infection. Therefore, the association of MV infection had been considered not to be significant in this case. Why did the fetus whose placenta was severely damaged survive and grow for more than 3 months? We speculate that one of the major reasons is monozygotic twinning. Vascular anastomoses, both superficial and deep ones, are common in the monochorionic placenta (6). Three large anastomoses were confirmed in the present case. Supplemental blood flow from the mildly affected twin might have protected the co-twin from life-threatening hypoxemia caused by extensive fibrin deposition. With the progress of gestation, the blood supply might have become insufficient to give nutrition to the co-twin. If the fetuses had not been monozygotic twins, the fetus whose placenta was severely affected might have died earlier.

It was peculiar that the placenta of one of the monozygotic twins was severely infected with MV and the placenta of the other was only mildly affected. Difference between monozygotic twins in susceptibility to MV has been reported in several reports, mainly dealing with subacute sclerosing panencephalitis (11-13). Although the reason remains unknown, the twin who died in utero might have been more susceptible to MV than the liveborn co-twin.

Transplacental infection of MV to the fetus is considered infrequent (14). In this case, as in the previously reported case (5), no evidence of active MV infection was found in the fetus, despite the diffuse MV infection in the villous trophoblast. One possible explanation is that the trophoblast played a defensive role for a considerable period that was enough for the mother to make anti-MV antibodies; thereafter, the antibodies transported to the fetus may have protected the fetal organs. Difference of susceptibility to MV between villous trophoblast and the other organs or cells may be another explanation. In any case, the stillbirth showed no gross or histologic findings suggestive of active MV infection. If the placenta had not been examined, the persistent MV infection of the placenta would have been overlooked. As a result, the cause of intrauterine death may have been misinterpreted and the infected placenta may have been the source of MV contamination. Both clinicians and pathologists should be aware that placental MV infection may persist for a longer period than expected, at least under certain conditions, and that histologic examination of the placenta can provide useful data for the precise interpretation of the fetal and maternal pathology.

\section{REFERENCES}

1. Ali ME, Albar HM. Measles in pregnancy: maternal morbidity and perinatal outcome. Int J Gynaecol Obstet 1997;59:10913.

2. Atmar RL, Englund JA, Hammill H. Complications of measles during pregnancy. Clin Infect Dis 1992;14:217-26.

3. Dao B, Koalaga AP, Ki Zerbo G, Bambara M, Bazie AJ. Measles and pregnancy. Apropos of 16 cases in Burkina Faso [French]. J Gynecol Obstet Biol Reprod (Paris) 1997;26:606-9.

4. Eberhart-Phillips JE, Frederick PD, Baron RC, Mascola L. Measles in pregnancy: a descriptive study of 58 cases. Obstet Gynecol 1993;82:797-801.

5. Moroi K, Saito S, Kurata T, Sata T, Yanagida M. Fetal death associated with measles virus infection of the placenta. Am J Obstet Gynecol 1991;164:1107-8.

6. Benirschke K. Multiple pregnancy. In: Benirschke K, Kaufmann P, editors. Pathology of human placenta. 4 th ed. New York: Springer; 2000. p. 790-902.

7. Sata T, Kurata T, Aoyama Y, Sakaguchi M, Yamanouchi K, Takeda K. Analysis of viral antigens in giant cells of measles pneumonia by immunoperoxidase method. Virchows Arch A Pathol Anat Histopathol 1986;410:133-8.

8. Centers for Disease Control. Measles-United States. MMWR Morb Mortal Wkly Rep 1991;40:369-72.

9. Vanderpuye OA, Labarrere CA, McIntyre JA. Glycosylation of membrane cofactor protein (CD46) in human trophoblast, kidney and platelets. Biochim Biophys Acta 1992; 1121:301-8.

10. Dorig RE, Marcil A, Richardson CD. CD46, a primate-specific receptor for measles virus. Trends Microbiol 1994;2:312-8.

11. Cianchetti C, Marrosu MG, Manconi PE, Loi M, Cao A. Subacute sclerosing panencephalitis in only one of identical twins. Case report with study of cell-mediated immunity. Eur Neurol 1983;22:428-32.

12. Houff SA, Madden DL, Sever JL. Subacute sclerosing panencephalitis in only one of identical twins. A seven-year followup. Arch Neurol 1979;36:854-6.

13. Park SY, Kohl S. Subacute sclerosing panencephalitis in an identical twin. Pediatrics 1999;104:1390-4.

14. Young NA, Gershon AA. Chickenpox, measles and mumps. In: Remington JS, Klein JO, editors. Infectious diseases of the fetus and newborn infant. 2nd ed. Philadelphia: Saunders; 1983. p. $375-427$. 